\title{
Protein synthesis and degradation gene SNPs related to feed intake, feed efficiency, growth, and ultrasound carcass traits in Nellore cattle
}

\author{
R.C. Gomes ${ }^{1}$, S.L. Silva ${ }^{1}$, M.E. Carvalho ${ }^{1}$, F.M. Rezende ${ }^{1}$, L.F.B. Pinto ${ }^{2}$, \\ M.H.A. Santana ${ }^{1}$, T.R. Stella ${ }^{1}$, F.V. Meirelles ${ }^{1}$, P. Rossi Júnior ${ }^{3}$, \\ P.R. Leme ${ }^{1}$ and J.B.S. Ferraz ${ }^{1}$ \\ ${ }^{1}$ Faculdade de Zootecnia e Engenharia de Alimentos, \\ Universidade de São Paulo, Pirassununga, SP, Brasil \\ ${ }^{2}$ Departamento de Produção Animal, Escola de Medicina Veterinária, \\ Universidade Federal da Bahia, Salvador, BA, Brasil \\ ${ }^{3}$ Departamento de Zootecnia, Universidade Federal do Paraná, \\ Curitiba, PR, Brasil \\ Corresponding author: R.C. Gomes \\ E-mail: gomes_rc@hotmail.com
}

Genet. Mol. Res. 12 (3): 2923-2936 (2013)

Received October 29, 2012

Accepted December 14, 2012

Published August 12, 2013

DOI http://dx.doi.org/10.4238/2013.August.12.8

ABSTRACT. We looked for possible associations of SNPs in genes
related to protein turnover, with growth, feed efficiency and carcass traits
in feedlot Nellore cattle. Purebred Nellore bulls and steers $(\mathrm{N}=290$;
$378 \pm 42 \mathrm{~kg}$ body weight, 23 months \pm 42 days old) were evaluated for
daily feed intake, body weight gain (BWG), gross feed efficiency, feed
conversion ratio, partial efficiency of growth, residual feed intake (RFI),
ultrasound backfat, rump fat, and ribeye area. Genotypes were obtained
for SNPs in the growth hormone receptor (GHR-1 and GHR-2); calpain
(CAPN4751); calpastatin (UoGCAST); ubiquitin-conjugating enzyme
2I (UBE2I-1 and UBE2I-2); R3H domain containing 1 (R3HDM1-1,
-2, -3, and -4), ring finger protein 19 (RNF19); proteasome 26S subunit,
non-ATPase, 13 (PSMD13); ribosomal protein, large, P2 (RPLP2); and 
isoleucine-tRNA synthetase 2, mitochondrial (IARS2) genes. Allelic substitution, additive and dominant effects were tested and molecular breeding values were computed. CAPN4751, GHR-1 and -2, IARS2, R3HDM1-4, and UoGCAST were found to be normally segregating polymorphisms. Additive and dominance effects were observed on BWG, feed efficiency and carcass traits, although dominant effects predominated. Significant allelic substitution effects were observed for CAPN4751, GHR-1 and -2, and UoGCAST on BWG, gross feed efficiency, RFI, and carcass traits, under single- or multiple-marker analyses. Correlations between molecular breeding values and phenotypes were low, excepted for RFI, based on allelic substitution estimates obtained by stepwise linear regression. We conclude that SNPs in genes related to protein turnover are related to economically important traits in Nellore cattle.

Key words: Bos indicus; Marker-assisted selection; Protein turnover; Molecular breeding value; Residual feed intake

\section{INTRODUCTION}

Growth in livestock occurs mainly as a function of deposition of muscle and adipose tissues in the body. The processes of protein synthesis and degradation, commonly called protein turnover, affect muscle growth rates and can consequently alter meat production traits in beef cattle.

Higher activities of protease inhibitors (e.g., calpastatin) have been related to decreased degradation rates of myofibril proteins in muscle and increased growth efficiency in cattle (Morgan et al., 1993). Additionally, protein degradation rates account, to a large extent, for variation in growth rate (Oddy et al., 1998) and energy requirements in beef cattle (Castro Bulle et al., 2007). Therefore, single nucleotide polymorphisms (SNPs) occurring in or nearby genes that act in the regulation of protein turnover may be useful as markers for growth and carcass traits.

A study by Barendse et al. (2007) reported several SNPs associated with feed efficiency in beef cattle. Among the SNPs analyzed, the authors described some polymorphisms located in genes affecting protein synthesis and degradation. Furthermore, polymorphisms in the growth hormone receptor (GHR) gene have been shown to be associated with growth in beef cattle (Sherman et al., 2008) and SNPs in the calpain gene have been tested for their association with meat tenderness and marbling (White et al., 2005; Casas et al., 2006) but not with growth traits, such as feed efficiency, or with carcass traits.

However, especially for feed efficiency traits, most of the studies identifying associated SNPs in beef cattle have been conducted in Bos primigenius taurus (B. p. taurus), but there are few studies on the association between SNPs and feed efficiency in Bos primigenius indicus (B. p. indicus). Furthermore, validation of molecular markers is a very important step for the use of marker-assisted selection in breeding programs.

Therefore, this study aimed to evaluate the associations of SNPs in genes related to protein degradation and synthesis identified in $B . p$. taurus, with growth, feed efficiency and ultrasound carcass traits in Nellore cattle, through the assessment of allelic substitution ef- 
fects, additive and dominant effects and the correlations between predicted molecular breeding values and adjusted phenotypes.

\section{MATERIAL AND METHODS}

\section{Population}

In the present study, all animals were handled following the principles postulated by the Brazilian College of Animal Experimentation (COBEA) that guarantee animal health and welfare. This research was also approved by the Ethics Committee of Faculdade de Zootecnia e Engenharia de Alimentos (FZEA), of Universidade de São Paulo (USP), located in Pirassununga, SP, Brazil.

The data set of this study was obtained from 290 Nellore bulls and steers evaluated in feeding trials carried out at FZEA-USP and at Universidade Federal do Paraná (UFPR), located in Curitiba, PR, Brazil. Cattle were raised under grazing (primarily Brachiaria spp) conditions until around 18 months of age, and they were then enrolled in feeding trials. The feeding trial period varied from 56 to 84 days, after an adaptation period of 21 to 28 days, established to adapt the cattle to the feedlot diet and to the place. Cattle were housed in individual pens and in group pens composed of Calan Broadbent feeding doors (American Calan Inc., Northwood, $\mathrm{NH}$, USA), with $25 \mathrm{~m}^{2}$ as a minimum space per animal. Individual and group pens were soil-surfaced and contained automatic water fountains. Animals were identified with ear tags, which were used for the individual control of all measurements taken during the feeding trials.

\section{Phenotypic traits}

Acronyms, trait means, and standard deviations (SD) are given in Table 1. Dry matter daily feed intake (DMI) was calculated as the difference between the amounts of feed offered and orts. Every 21 or 28 days throughout the experiments, cattle were weighed after $16 \mathrm{~h}$ of food withdrawal. The body weight gain (BWG) was obtained through the regression of body weight (BW) against feeding time (days), and the mid-test body weight (MBW) was calculated as the average between initial and final BW.

Table 1. Abbreviations, overall trait means, and standard deviation (SD) in experimental cattle.

\begin{tabular}{|c|c|c|c|}
\hline Trait & Abbreviation & Average & SD \\
\hline Age (days) & - & 666 & 65 \\
\hline Mid-test body weight (kg) & MBW & 428 & 46 \\
\hline Dry matter intake (kg/day) & DMI & 9.52 & 1.38 \\
\hline Metabolizable energy intake (Mcal/day) & MEI & 23.7 & 3.4 \\
\hline Average daily body weight gain (kg/day) & BWG & 1.51 & 0.38 \\
\hline Gross feed efficiency $(\mathrm{kg} / \mathrm{kg})$ & GFE & 0.159 & 0.034 \\
\hline Feed conversion ratio $(\mathrm{kg} / \mathrm{kg})$ & FCR & 6.60 & 1.56 \\
\hline Partial efficiency of growth (g/kg) & PEG & 0.315 & 0.091 \\
\hline Residual feed intake a (kg/day) & RFIa & 0.00 & 1.03 \\
\hline Residual feed intake w (kg/day) & RFIw & 0.00 & 0.70 \\
\hline Ultrasound rib eye area $\left(\mathrm{cm}^{2}\right)$ & UREA & 71.7 & 9.1 \\
\hline Ultrasound rib eye area $\left(\mathrm{cm}^{2} 100 \mathrm{~kg} / \mathrm{BW}\right)$ & UREA/BW & 0.151 & 0.015 \\
\hline Ultrasound backfat thickness (mm) & UBFT & 3.81 & 1.58 \\
\hline Ultrasound rump fat thickness (mm) & URFT & 6.47 & 2.52 \\
\hline
\end{tabular}

RFIa $=$ residual feed intake computed across contemporary groups; RFIw = residual feed intake computed within contemporary groups. 
Gross feed efficiency (GFE) and feed conversion ratio (FCR) were determined by the ratios between BWG and DMI. Partial efficiency of growth (PEG) was obtained as the ratio between BWG and the difference of actual DMI and expected DMI for maintenance.

DMI for maintenance was estimated using requirement tables developed for the Nellore breed (122 and $119 \mathrm{kcal} \mathrm{ME} / \mathrm{kg} \mathrm{BW}^{0.75}$ for bulls and steers, respectively; Valadares Filho et al., 2006). Residual feed intake (RFI) was calculated as the difference between the actual feed intake and the expected feed intake, which was determined by regressing DMI against $\mathrm{MBW}^{0.75}$ and BWG, respectively. Sex and contemporary group were included as class variables to compute RFI across contemporary groups (RFIa), which accounted for differences across feeding trials. Individual RFI was also calculated within contemporary groups, including sex as class variable, when needed (RFIw).

Cattle were ultrasound scanned using an Aloka 500V real-time ultrasound with a 17$\mathrm{cm}, 3.5 \mathrm{MHz}$ linear array transducer. These measurements were taken in the beginning and at the end of each feeding trial by trained personnel. Ultrasound backfat thickness (UBFT) and ultrasound ribeye area (UREA) were measured on the longissimus muscle between the 12th and 13th ribs. Ultrasound rump fat thickness (URFT) was measured on the biceps femoris muscle (P8). UREA per $100 \mathrm{~kg}$ final BW ratio was calculated as an indirect measure of muscularity.

\section{Genotyping and molecular markers}

Genomic DNA was obtained by $\mathrm{NaCl}$ extraction (Olerup and Zetterquist, 1992) from whole blood drawn by venipuncture of the jugular vein. Allelic discrimination was performed using TaqMan $^{\circledR}$ Real-Time PCR assays in an ABI Prism ${ }^{\circledR} 7500$ Sequence Detection System (Applied Biosystems, Foster City, CA, USA) and LightCycler ${ }^{\circledR}$ Real-Time PCR System (Roche Applied Science, Mannheim, Germany). Information on the polymorphisms evaluated is summarized in Table 2.

\begin{tabular}{|c|c|c|c|c|c|}
\hline Gene & BTA & SNP ID & Location & Accession No. -base position/dbSNP reference & Mutation \\
\hline CAST & 7 & UoGCAST & Intron 5 & AY008267-282 & $\mathrm{C} / \mathrm{G}$ \\
\hline CALP1 & 29 & CAPN4751 & Intron 18 & AF248054-6545 & $\mathrm{C} / \mathrm{T}$ \\
\hline \multirow[t]{2}{*}{ GHR } & 20 & GHR-1 & Promoter & AF126288-149 & $\mathrm{A} / \mathrm{G}$ \\
\hline & & GHR-2 & Intron 4 & AY643807-300 & $\mathrm{A} / \mathrm{G}$ \\
\hline \multirow[t]{2}{*}{ UBE2I } & 6 & UBE2I-1 & $\mathrm{N} / \mathrm{I}$ & rs29019637 & $\mathrm{A} / \mathrm{T}$ \\
\hline & & UBE2I-2 & $\mathrm{N} / \mathrm{I}$ & rs42055278 & $\mathrm{A} / \mathrm{G}$ \\
\hline IARS2 & 16 & IARS2 & $\mathrm{N} / \mathrm{I}$ & rs41257031 & $\mathrm{C} / \mathrm{T}$ \\
\hline RPLP2 & 5 & RPLP2 & $\mathrm{N} / \mathrm{I}$ & rs29022979 & $\mathrm{A} / \mathrm{G}$ \\
\hline PSMD13 & 29 & PSMD13 & $\mathrm{N} / \mathrm{I}$ & rs29021673 & $\mathrm{A} / \mathrm{G}$ \\
\hline RNF19 & 14 & RNF19 & $\mathrm{N} / \mathrm{I}$ & rs29027340 & $\mathrm{C} / \mathrm{T}$ \\
\hline \multirow[t]{4}{*}{ R3HDM1 } & 2 & R3HDM1-1 & $\mathrm{N} / \mathrm{I}$ & rs29011612 & $\mathrm{A} / \mathrm{G}$ \\
\hline & & R3HDM1-2 & $\mathrm{N} / \mathrm{I}$ & rs29021802 & $\mathrm{G} / \mathrm{T}$ \\
\hline & & R3HDM1-3 & $\mathrm{N} / \mathrm{I}$ & rs 29021801 & $\mathrm{C} / \mathrm{G}$ \\
\hline & & R3HDM1-4 & $\mathrm{N} / \mathrm{I}$ & rs29014564 & $\mathrm{C} / \mathrm{T}$ \\
\hline
\end{tabular}

BTA = Bos taurus chromossome. $\mathrm{N} / \mathrm{I}=$ information about the location of the polymorphisms in the respective gene was not available.

Nine SNPs were compiled and chosen from Barendse et al. (2007). According to these authors, the SNPs were identified in the follow genes: R3H domain containing 1 (R3HDM1-1, R3HDM1-2, R3HDM1-3, and R3HDM1-4) on chromosome 2; ubiquitinconjugating enzyme E2I (UBC9 homolog, yeast) (UBE2I-1) on chromosome 6; mitochondrial isoleucine-tRNA synthetase 2 (IARS2) on chromosome 16; ribosomal protein, large, 
P2 (RPLP2) on chromosome 5; proteasome 26S subunit, non-ATPase, 13 (PSMD13) on chromosome 29; and ring finger protein 19 (RNF19), $70 \mathrm{kbp}$ to left (RFP19) on chromosome 14. These genes are associated with mechanisms of protein degradation (R3HDM1, UBE2I, PSMD13, and RNF19) and protein synthesis (IARS2 and RPLP2). The other five polymorphisms were also studied because of their relationship with proteolysis and muscle growth in cattle. CAPN4751 is a polymorphism located in intron 18 (base 6545 of AF248054) of the calpain gene (CALP1, GenBank accession No. AF248054) located on chromosome 29. According to White et al. (2005), this SNP is a silent mutation resulting from a cytosine/thymine substitution $(\mathrm{C} / \mathrm{T})$. The CAST gene (GenBank accession No. AY008267) is located on chromosome 7, and the UoGCAST polymorphism is a substitution of cytosine with guanine $(\mathrm{C} / \mathrm{G})$ located in intron 5 (base 282 of AY008267) (Schenkel et al., 2006). Another SNP in the UBE2I gene (chromosome 6; Antoniou and Gallagher, 2002) reported in GenBank (refSNP: rs42055278) was chosen to be evaluated. GHR-1 is an adenine to guanine substitution in the promoter region of the GHR gene (GenBank accession No. AF126288, position 149) described by Ge et al. (1999). In intron 4 of the same gene, Maj and Zwierzchowski (2006) reported an A/G substitution (GenBank accession No. AY643807, position 300) called GHR-2 herein.

\section{Statistical analysis}

Gene and genotypic frequencies for each marker were estimated by simple count of different alleles and genotypes, using PROC FREQ in SAS (SAS, 2004). Association analyses between SNP and traits were conducted with PROC MIXED, using a mixed model:

$$
\mathrm{Y}_{\mathrm{ijk}}=\mu+\mathrm{CG}_{\mathrm{i}}+\mathrm{S}_{\mathrm{j}}+\alpha_{1}(\text { age })+\alpha_{2}(\text { days on feed })+\alpha_{3}(\text { genotype })+\mathrm{si}_{\mathrm{k}}+e_{\mathrm{ijk}}
$$

where $Y_{i j k}=$ phenotypic value of the trait; $\mu$ = general mean of the trait; $C G_{i}=$ fixed effect of contemporary group (feeding trails 1 to 5 ); $S_{j}=$ fixed effect of sex (steers and bulls); $\alpha_{1}=$ regression coefficient of covariate of age at the measurement; $\alpha_{2}=$ regression coefficient of covariate of days on feeding; $\alpha_{3}=$ regression coefficient associated with the number of favorable alleles for each marker; $s i_{k}=$ random effect of sire $\left[\mathrm{si}_{\mathrm{k}} \sim \mathrm{N}\left(0, \sigma_{\mathrm{s}}^{2}\right)\right]$; and $e_{i j k}=$ random residual error $\left[\mathrm{e}_{\mathrm{ijk}} \sim \mathrm{N}\left(0, \sigma_{\mathrm{e}}^{2}\right)\right]$.

Days on feeding was not significant on BW, DMI, BWG, GFE, FCR, PEG, RFIa, initial UBFT, initial and final URFT and initial UREA, and therefore, it was excluded from the model for these traits. The same was done for age on measurement of GFE, FCR, PEG, RFIw, RFIa, and initial URFT.

Additive effect was estimated as the difference between the two homozygous means (Falconer and Mackay, 1996). Dominance effect was estimated as the deviation of the heterozygote from the mean of the two homozygotes (Falconer and Mackay, 1996). The average allele substitution effect was estimated by regressing the phenotype against the number of copies of one allele of only one SNP using the cited mixed model in SAS.

Three approaches were considered to estimate the allelic substitution effects. In the first, each polymorphism was analyzed individually, whereas in the second, a multiple-marker analysis was conducted, including all SNPs in the model. In the third method, the adjusted phenotypes were submitted to least square estimation, using stepwise regres- 
sion in SAS and including all SNPs as independent variables in the model. In that procedure, the significance level for the SNP to be introduced and kept in the model was set at 20 and $10 \%$, respectively.

The allelic substitution effect estimates were used to compute individual molecular breeding values (MBV) for each trait by multiplying the number of copies of the favorable allele by the respective substitution effect estimated. The model predictive ability was assessed by the Pearson correlation between adjusted phenotype and estimated MBV. Phenotypes were adjusted for all effects described in the model above using their estimations obtained in the present study.

\section{RESULTS}

Six SNP were not polymorphic and showed the following fixed genotypes: CC for RNF19, GG for RPLP2, AA for R3HDM1-1, TT for R3HDM1-2, CC for R3HDM1-3, and GG for UBE2I-2 (Table 3). The SNP R3HDM1-4 showed the following allelic and genotypic frequencies $\mathrm{C}=0.31, \mathrm{~T}=0.69, \mathrm{CC}=0.18, \mathrm{CT}=0.26$, and $\mathrm{TT}=0.56$.

\begin{tabular}{|c|c|c|c|c|c|}
\hline \multirow{2}{*}{$\begin{array}{l}\text { Marker } \\
\text { R3HDM1-1 }\end{array}$} & \multicolumn{2}{|c|}{ Allele frequency } & \multicolumn{3}{|c|}{ Genotypic frequency } \\
\hline & A -1.00 & $\mathrm{G}-0.00$ & $f(A A)=1.00$ & $f(A G)=0.00$ & $\mathrm{f}(\mathrm{GG})=0.00$ \\
\hline R3HDM1-2 & $G-0.00$ & $\mathrm{~T}-1.00$ & $\mathrm{f}(\mathrm{GG})=0.00$ & $\mathrm{f}(\mathrm{GT})=0.00$ & $f(T T)=1.00$ \\
\hline R3HDM1-3 & $C-1.00$ & $G-0.00$ & $f(C C)=1.00$ & $\mathrm{f}(\mathrm{CG})=0.00$ & $\mathrm{f}(\mathrm{GG})=0.00$ \\
\hline R3HDM1-4 & C -0.31 & $\mathrm{~T}-0.69$ & $f(C C)=0.18$ & $f(C T)=0.26$ & $\mathrm{f}(\mathrm{TT})=0.56$ \\
\hline UBE2I-1 & A -0.33 & $\mathrm{~T}-0.67$ & $f(A A)=0.21$ & $f(A T)=0.24$ & $\mathrm{f}(\mathrm{TT})=0.55$ \\
\hline UBE2I-2 & A -0.00 & $G-1.00$ & $f(A A)=0.00$ & $f(A G)=0.00$ & $\mathrm{f}(\mathrm{GG})=1.00$ \\
\hline RNF19 & $C-1.00$ & $\mathrm{~T}-0.00$ & $f(C C)=1.00$ & $f(C T)=0.00$ & $\mathrm{f}(\mathrm{TT})=0.00$ \\
\hline PSMD13 & A -0.03 & $G-0.97$ & $f(\mathrm{AA})=0.00$ & $\mathrm{f}(\mathrm{AG})=0.05$ & $\mathrm{f}(\mathrm{GG})=0.95$ \\
\hline RPLP2 & A -0.00 & $\mathrm{G}-1.00$ & $f(\mathrm{AA})=0.00$ & $f(A G)=0.00$ & $\mathrm{f}(\mathrm{GG})=1.00$ \\
\hline IARS2 & $C-0.78$ & $\mathrm{~T}-0.22$ & $f(C C)=0.63$ & $\mathrm{f}(\mathrm{CT})=0.32$ & $\mathrm{f}(\mathrm{TT})=0.06$ \\
\hline CAPN4751 & $C-0.13$ & $\mathrm{~T}-0.87$ & $\mathrm{f}(\mathrm{CC})=0.02$ & $\mathrm{f}(\mathrm{CT})=0.22$ & $\mathrm{f}(\mathrm{TT})=0.76$ \\
\hline UoGCAST & $C-0.55$ & $G-0.45$ & $f(C C)=0.29$ & $\mathrm{f}(\mathrm{CG})=0.51$ & $\mathrm{f}(\mathrm{GG})=0.20$ \\
\hline GHR-1 & A - 0.03 & G - 0.97 & $f(\mathrm{AA})=0.00$ & $\mathrm{f}(\mathrm{AG})=0.05$ & $\mathrm{f}(\mathrm{GG})=0.95$ \\
\hline GHR-2 & A -0.20 & $G-0.80$ & $f(\mathrm{AA})=0.02$ & $f(A G)=0.36$ & $\mathrm{f}(\mathrm{GG})=0.62$ \\
\hline
\end{tabular}

Although the PSMD13 displayed both A and G alleles, the A allele was rare (3\%), the AA genotype was not found ( $0 \%)$, and the AG frequency was very low $(5 \%)$. In turn, the UBE2I-1 showed good segregation with a minor allele frequency (MAF) of 0.33 for the A allele and genotypic frequencies of $0.21,0.24$, and 0.55 for the AA, AT, and TT types. A good segregation was observed for IARS2, with allelic and genotypic frequencies of 0.78 and 0.22 for the $\mathrm{C}$ and $\mathrm{T}$ alleles and $0.63,0.32$, and 0.06 for the $\mathrm{CC}, \mathrm{CT}$, and TT genotypes, respectively. GHR-1 showed low frequencies of the A allele (3\%) and did not show the AA genotype. In contrast, the minor allele frequency for GHR-2 was much greater $(20 \%$, A allele) and all three genotypes were observed, despite the small frequency for $\mathrm{AA}(2 \%)$.

Suggestive $(\mathrm{P}<0.10)$ and significant $(\mathrm{P}<0.05)$ allelic substitution effects were seen for CAPN4751, UoGCAST, GHR-1, and GHR-2 (Table 4). Suggestive effects were observed on BWG for CAPN4751, on GFE for UoGCAST, on PEG and RFIw for GHR-2, and on final UREA for GHR-1. Significant effects were observed on BWG and UREA/BW for UoGCAST and on initial and final URFT for GHR-1 and CAPN4751, respectively. 
Table 4. Allelic substitution effects of markers on growth, feed efficiency, and carcass traits in Nellore cattle, using a single marker analysis approach.

\begin{tabular}{llcccc}
\hline Trait & Marker & Estimate & SE & P & Favorable allele \\
\hline BWG & CAPN4751 & -0.075 & 0.039 & 0.0555 & $\mathrm{C}$ \\
& UoGCAST & -0.072 & 0.026 & 0.0066 & $\mathrm{C}$ \\
GFE & UoGCAST & -0.004 & 0.002 & 0.0718 & $\mathrm{C}$ \\
RFIw & GHR-2 & 0.152 & 0.084 & 0.0719 & $\mathrm{~A}$ \\
URFT initial & GHR-1 & -1.371 & 0.488 & 0.0054 & $\mathrm{~A}$ \\
URFT final & CAPN4751 & -0.730 & 0.335 & 0.0303 & $\mathrm{C}$ \\
UREA final & GHR-1 & 3.381 & 2.040 & 0.0988 & $\mathrm{G}$ \\
UREA/BW & UoGCAST & 0.003 & 0.001 & 0.0499 & $\mathrm{G}$ \\
\hline
\end{tabular}

For trait abbreviations, see Table 1.

When using the multiple-marker model (Table 5), the effects of GHR-2 on PEG became suggestive $(\mathrm{P}=0.0984)$ with an estimate of $-0.0135 \mathrm{~kg} / \mathrm{kg}(\mathrm{SE}=0.0082)$, whereas the UoGCAST effects on GFE and the GHR-2 effects on RFIw was no longer at the suggestive significance level $(\mathrm{P}>0.10)$. A suggestive allelic substitution effect of R3HDM1-4 on initial UBFT $(-0.15 \mathrm{~mm}, \mathrm{SE}=0.090, \mathrm{P}=0.0952)$ was observed. The effect of UoGCAST on UREA/ $\mathrm{BW}$, which had previously reached the significant level $(\mathrm{P}<0.05)$, was no longer at the suggestive significance level $(\mathrm{P}=0.1230)$ when evaluated by the multiple-marker model, exhibiting the greatest shift among all markers.

Table 5. Significance (P value) of allelic substitution effects of markers on growth, feed efficiency, and carcass traits, using a multi-marker model approach.

\begin{tabular}{|c|c|c|c|c|c|c|c|c|}
\hline \multirow[t]{2}{*}{ Trait } & \multicolumn{8}{|c|}{ Marker } \\
\hline & CAPN4751 & GHR-1 & GHR-2 & IARS2 & R3HDM1-4 & PSMD13 & UBE2I-1 & UoGCAST \\
\hline$\overline{M B W}$ & 0.3970 & 0.4980 & 0.7152 & 0.4373 & 0.9804 & 0.6439 & 0.6339 & 0.9748 \\
\hline DMI & 0.4546 & 0.1927 & 0.5280 & 0.3791 & 0.4938 & 0.6051 & 0.2453 & 0.4235 \\
\hline BWG & 0.0563 & 0.4164 & 0.4623 & 0.1112 & 0.3526 & 0.1954 & 0.1602 & 0.0112 \\
\hline GFE & 0.1268 & 0.9841 & 0.1242 & 0.3362 & 0.7106 & 0.3497 & 0.4905 & 0.1005 \\
\hline FCR & 0.1536 & 0.8378 & 0.2275 & 0.4163 & 0.3254 & 0.3603 & 0.1939 & 0.2427 \\
\hline PEG & 0.4841 & 0.8765 & 0.0984 & 0.8779 & 0.5900 & 0.6812 & 0.9988 & 0.5320 \\
\hline RFIw & 0.6179 & 0.7079 & 0.1146 & 0.4727 & 0.4205 & 0.6879 & 0.6573 & 0.8223 \\
\hline RFIa & 0.3075 & 0.5508 & 0.1139 & 0.6050 & 0.9261 & 0.5014 & 0.5872 & 0.9267 \\
\hline UBFT initial & 0.3144 & 0.4845 & 0.8536 & 0.6887 & 0.0952 & 0.7970 & 0.8086 & 0.2086 \\
\hline UBFT final & 0.9526 & 0.9343 & 0.8289 & 0.4889 & 0.1686 & 0.7047 & 0.4515 & 0.5752 \\
\hline URFT initial & 0.3794 & 0.0079 & 0.6792 & 0.7391 & 0.4714 & 0.5966 & 0.6058 & 0.4784 \\
\hline URFT final & 0.0187 & 0.4381 & 0.6046 & 0.4472 & 0.4593 & 0.5224 & 0.9940 & 0.9626 \\
\hline UREA initial & 0.9870 & 0.1846 & 0.7241 & 0.2980 & 0.9096 & 0.1815 & 0.3359 & 0.3024 \\
\hline UREA final & 0.8081 & 0.0634 & 0.4445 & 0.9198 & 0.5826 & 0.3110 & 0.7949 & 0.2084 \\
\hline UREA/BW & 0.4421 & 0.1415 & 0.3259 & 0.3959 & 0.7068 & 0.5186 & 0.8676 & 0.1230 \\
\hline
\end{tabular}

For trait abbreviations, see Table 1.

In the stepwise regression analyses, the models demonstrated low $\mathrm{R}^{2}$ values $(0.02$ to 0.14 ; Table 6). The dry matter intake was the trait that was most explained by the stepwise regressions model $\left(\mathrm{R}^{2}=0.15\right)$. Except for BWG, RFIw, initial UBFT, and initial UREA, all traits had more than one significant SNP entering into the model. The CAPN4751, R3HDM1-4, and UBE2I-1 were significant in 8 of 15 traits that were evaluated. R3HDM1-4 had effects on most of the feed efficiency traits (GFE, FCR, PEG, and RFIa), whereas CAPN4751 and UBE2I-1 exhibited most of their effects on carcass traits (URFT, UBFT, and UREA).

The coefficients of correlation between molecular breeding values and adjusted phenotypes were low and non-significant in most cases when the multiple-marker model was em- 
ployed (Table 7). Conversely, correlations of the MBV generated by stepwise regression were greater and significant most of the time, as noted for feed intake and carcass traits. However, there was an exception for the association between MBV and adjusted RFIw, regardless of the significance level adopted. Coefficients were around 0.50 , a value much greater than that obtained for the correlation between MBV and other traits.

\begin{tabular}{|c|c|c|c|c|c|c|c|c|c|c|c|}
\hline Trait' ${ }^{2}$ & Intercept & CAPN4751 & GHR-1 & GHR-2 & IARS2 & R3HDM1-4 & UBE2I-1 & UoGCAST & Model R-Sq. & $\mathrm{C}(\mathrm{p})$ & $P>F$ \\
\hline MBW & $372.8^{* * *}$ & $11.76^{*}$ & $17.91^{\dagger}$ & - & $-8.56^{*}$ & - & $-6.64^{*}$ & $6.46^{+}$ & 0.0933 & 4.5891 & 0.0002 \\
\hline DMI & $10.26 * * *$ & - & $-0.445^{*}$ & $-0.312^{* *}$ & - & - & $0.232 * * *$ & $-0.142^{*}$ & 0.1474 & 4.8013 & $<0.0001$ \\
\hline BWG & $1.53^{* * * *}$ & - & - & - & - & $-0.083 * * *$ & - & - & 0.0585 & 0.6938 & $<0.0001$ \\
\hline GFE & $0.160^{* * *}$ & $0.0050^{\dagger}$ & - & - & - & $-0.0079 * * *$ & - & - & 0.0780 & -1.5717 & $<0.0001$ \\
\hline FCR & $6.52 * * *$ & $-0.225^{\dagger}$ & - & - & - & $0.272^{* *}$ & - & - & 0.0660 & 1.2247 & 0.0004 \\
\hline PEG & $0.223 * * *$ & $0.0251^{* *}$ & $0.0304^{*}$ & $0.0168^{*}$ & - & $-0.0166^{* *}$ & $-0.0126^{*}$ & - & 0.1212 & 5.4035 & $<0.0001$ \\
\hline RFIw & $0.038^{*}$ & - & - & $0.0022^{*}$ & - & - & - & - & 0.0186 & -1.1103 & 0.0294 \\
\hline RFIa & $0.049^{\text {ns }}$ & - & $-0.2062^{\dagger}$ & - & - & $0.1215^{* *}$ & $0.0757^{*}$ & - & 0.0691 & -0.1041 & 0.0004 \\
\hline UBFT initial & $0.69^{*}$ & - & $0.343^{*}$ & - & - & - & - & - & 0.0211 & 0.8704 & 0.0200 \\
\hline UBFT final & $3.99 * * *$ & - & - & $-0.225^{* *}$ & - & - & $0.109^{*}$ & - & 0.0486 & 3.0452 & 0.0018 \\
\hline URFT initial & $3.58 * * *$ & $-0.346^{*}$ & - & $-0.377^{* *}$ & $0.184^{\dagger}$ & - & $0.227^{* *}$ & - & 0.1007 & 4.6850 & $<0.0001$ \\
\hline URFT final & $7.43 * * *$ & $-0.280^{*}$ & - & $-0.474 * * *$ & - & - & $0.244 * *$ & - & 0.1136 & 2.4327 & $<0.0001$ \\
\hline UREA initial & $60.0^{* * *}$ & - & - & - & - & $-1.83^{* * *}$ & - & - & 0.0606 & 0.3687 & $<0.0001$ \\
\hline UREA final & $68.6^{* * *}$ & $3.17^{* * * *}$ & - & - & $-1.13^{\dagger}$ & $-0.90^{\dagger}$ & $-0.95^{*}$ & - & 0.1006 & 6.1401 & $<0.0001$ \\
\hline UREA/BW & $0.497 * * *$ & $0.0316^{* *}$ & - & - & $-0.0119^{\dagger}$ & $0.0126^{*}$ & 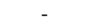 & - & 0.0809 & 3.7323 & $<0.0001$ \\
\hline
\end{tabular}

${ }^{n} \mathrm{P}>0.10 ;{ }^{\dagger} \mathrm{P}<0.10 ; * \mathrm{P}<0.05 ; * * \mathrm{P}<0.01 ; * * * \mathrm{P}<0.0001 .{ }^{1}$ The PSMD13 did not reach the significance level to enter $(\mathrm{P}<0.20)$ into the model. For trait abbreviations, see Table 1.

Table 7. Pearson's correlation analysis among adjusted phenotypes and the respective molecular breeding values estimated as a function of the significance level of individual marker estimate.

\begin{tabular}{|c|c|c|c|c|c|c|c|}
\hline \multirow[t]{2}{*}{ Trait } & \multicolumn{7}{|c|}{ Marker significance level } \\
\hline & $\mathrm{P}<1.00$ & $\mathrm{P}<0.80$ & $\mathrm{P}<0.60$ & $\mathrm{P}<0.40$ & $\mathrm{P}<0.20$ & $\mathrm{P}<0.10$ & Stepwise regression \\
\hline MBW & $0.17 * *$ & $0.16^{* *}$ & $0.11^{\dagger}$ & $0.16^{* *}$ & $0.18 * *$ & - & 0.04 \\
\hline DMI & 0.00 & 0.01 & 0.01 & 0.03 & 0.10 & 0.02 & $0.39 * * *$ \\
\hline BWG & 0.03 & 0.03 & 0.03 & 0.03 & 0.06 & 0.07 & $-0.19 * *$ \\
\hline GFE & -0.08 & -0.08 & -0.05 & -0.08 & -0.03 & -0.04 & $-0.25 * * *$ \\
\hline FCR & -0.11 & -0.10 & -0.10 & -0.10 & -0.11 & 0.06 & $-0.26 * * *$ \\
\hline PEG & -0.08 & 0.06 & -0.07 & $-0.14 *$ & $-0.17 * *$ & $-0.17 * *$ & -0.01 \\
\hline RFIw & $0.47 * * *$ & $0.47 * * *$ & $0.50 * * *$ & $0.48 * * *$ & $0.53 * * *$ & $0.53 * * *$ & $0.14 *$ \\
\hline RFIa & -0.02 & 0.02 & 0.01 & -0.02 & 0.01 & 0.00 & -0.05 \\
\hline UBFT initial & 0.05 & 0.05 & 0.05 & 0.05 & 0.10 & 0.08 & $0.15^{*}$ \\
\hline UBFT final & 0.03 & 0.06 & 0.07 & 0.06 & 0.09 & 0.10 & $0.22 * *$ \\
\hline URFT initial & $-0.10^{\dagger}$ & $-0.10^{\dagger}$ & $-0.11^{\dagger}$ & $-0.10^{\dagger}$ & -0.08 & -0.03 & 0.09 \\
\hline URFT final & -0.06 & -0.06 & -0.10 & -0.06 & $-0.16^{*}$ & $-0.16^{*}$ & $0.23 * *$ \\
\hline UREA initial & $0.13^{*}$ & $0.12^{\dagger}$ & $0.12^{\dagger}$ & $0.12^{\dagger}$ & $0.12^{\dagger}$ & 0.09 & $-0.25 * * *$ \\
\hline UREA final & 0.08 & 0.06 & 0.07 & 0.06 & $0.12^{\dagger}$ & 0.08 & $-0.22 * *$ \\
\hline UREA/BW & -0.06 & -0.05 & -0.08 & 0.01 & 0.00 & -0.01 & $-0.28 * * *$ \\
\hline
\end{tabular}

${ }^{\dagger} \mathrm{P}<0.10 ; * \mathrm{P}<0.05 ; * * * \mathrm{P}<0.01 ; * * * \mathrm{P}<0.0001$. For trait abbreviations, see Table 1.

In addition to the allelic substitution analyses, contrasts were tested to evaluate additive and dominant effects of markers (Table 8). Due to the low MAF, those effects were not assessed for GHR-1. Noteworthy is the magnitude of dominant effects found on MBW for CAPN4751 $(-23.2 \mathrm{~kg}, \mathrm{P}=0.017)$ and GHR-2 $(15.1 \mathrm{~kg}, \mathrm{P}=0.038)$, the additive effect of UoGCAST on BWG $(0.139 \mathrm{~kg} /$ day, $\mathrm{P}=0.009)$, the additive effect of IARS2 on FCR (-0.675, $\mathrm{P}=0.055$ ), and the GHR-2 effects on RFIa (dominant, $0.469 \mathrm{~kg} /$ day, $\mathrm{P}=0.016$ ) and on initial URFT (additive, $1.39 \mathrm{~mm}, \mathrm{P}=0.027$; dominant, $0.97 \mathrm{~mm}, \mathrm{P}=0.007$ ). 
Table 8. Significant $(\mathrm{P}<0.05)$ and suggestive $(0.05 \leq \mathrm{P} \geq 0.10)$ effects of markers in genes related to protein turnover, on growth, feed efficiency, and carcass traits in Nellore cattle.

\begin{tabular}{llccc}
\hline Trait & Marker & Effect & Estimate (SE) & P \\
\hline MBW & CAPN4751 & D & $-23.2(9.59)$ & 0.0166 \\
& GHR-2 & $15.1(7.22)$ & 0.0375 \\
BWG & R3HDM1-4 & D & $-9.6(5.04)$ & 0.0585 \\
& R3HDM1-4 & D & $-0.088(0.041)$ & 0.0338 \\
& UBE2I-1 & D & $-0.077(0.047)$ & 0.1043 \\
GFE & UoGCAST & A & $0.139(0.053)$ & 0.0090 \\
& GHR-2 & A & $-0.010(0.005)$ & 0.0718 \\
& R3HDM1-4 & D & $-0.006(0.004)$ & 0.1008 \\
FCR & UoGCAST & D & $0.008(0.005)$ & 0.1042 \\
& IARS2 & A & $-0.675(0.350)$ & 0.0550 \\
& IARS2 & D & $0.438(0.215)$ & 0.0431 \\
& R3HDMI-4 & D & $0.296(0.180)$ & 0.1019 \\
PEG & UBE2I-1 & D & $0.341(0.207)$ & 0.1000 \\
& GHR-2 & A & $-0.023(0.013)$ & 0.0777 \\
RFIw & R3HDM1-4 & D & $-0.015(0.009)$ & 0.0991 \\
RFIa & UoGCAST & D & $-0.145(0.087)$ & 0.0972 \\
UBFT initial & GHR-2 & D & $0.469(0.194)$ & 0.0163 \\
& GHR-2 & D & $0.46(0.22)$ & 0.0430 \\
URFT initial & R3HDM1-4 & A & $0.30(0.18)$ & 0.0882 \\
UREA/BW & GHR-2 & A & $1.39(0.63)$ & 0.0272 \\
& GHR-2 & D & $0.97(0.35)$ & 0.0069 \\
& CAPN4751 & D & $0.007(0.004)$ & 0.0834 \\
& GHR-2 & D & $-0.006(0.003)$ & 0.0550 \\
& UoGCAST & A & $-0.005(0.003)$ & 0.0535 \\
\hline
\end{tabular}

$\mathrm{SE}=$ standard error; $\mathrm{A}=$ additive effect; $\mathrm{D}=$ dominant effect. For trait abbreviations, see Table 1.

\section{DISCUSSION}

The aim of this research was to evaluate the association of polymorphisms located in genes considered candidates for involvement in the expression of growth, feed intake, feed efficiency, and carcass traits in feedlot beef cattle. Of the fixed SNPs, all except for UBE2I-2 and R3HDM1-4 were reported in a whole genome association study carried out by Barendse et al. (2007), which identified polymorphisms significantly associated with feed efficiency in beef cattle.

The R3HDM1-4 polymorphism was reported in the dbSNP Build 133 database, and unlike other known SNPs in the R3HDM1 gene region, it showed good allele and genotype frequencies. In the dbSNP Build 133 for cow database, the MAF for R3HDM1-1, R3HDM1-2, R3HDM1-3, and R3HDM1-4 were 0.00 to 0.17 (G allele), 0.00 to 0.17 (G allele), 0.00 to 0.17 (C allele), and 0.25 to 0.31 (T allele), respectively, similar to the present results.

No scientific results on population diversity for UBE2I-1, UBE2I-2, RNF19, and PSMD13 were found in Nellore cattle. However, except for UBE2I-1, they appear to be fixed and thus provide no helpful information on marker-assisted selection for productive traits in this breed. These SNPs have in common an association with the ubiquitin-proteasome pathway, which ultimately degrades 80 to $90 \%$ of all cellular proteins (Goll et al., 2008), after their modification with ubiquitin chains, by the action of E1, E2, and E3 enzymes (Ciechanover, 1998; Hershko and Ciechanover, 1998). The UBE2I gene encodes a member of the E2 enzyme family, which is involved in altering several cellular processes (Johnson, 2004; Zhao, 2007; Ihara et al., 2008). In turn, the RNF19 gene encodes a ring finger domain of ubiquitin protein ligases that act as regulators of the ubiquitin-mediated muscle proteolytic pathways (Lorick 
et al., 1999; Niwa et al., 2001; Vogiatzis et al., 2010) and the PSMD13 gene encodes the 26S proteasome subunit 13 , acting as a regulatory subunit of the $26 \mathrm{~S}$ proteasome. In the dbSNP Build 133 for cow database, MAF ranges from 0.00 to 0.17 (T allele) for UBE2I-1, 0.30 (C allele) to 0.42 (T allele) for RNF19, and 0.32 (A allele) to 0.45 (G allele) for PSMD13, while no frequency data for UBE2I-2 were found.

Unlike the other genes previously discussed, the RPLP2 and IARS2 genes are involved in translation and protein synthesis. The RPLP2 gene encodes one of the proteins that compose the ribosome molecular complex (Artero-Castro et al., 2011) and the IARS2 gene encodes an aminoacyl-transfer synthetase, which catalyzes the attachment of amino acids to its cognate transfer RNA molecule (Eriani et al., 1990), during the elongation step of protein synthesis. The RPLP2 was not polymorphic in the present study, which is in disagreement with the dbSNP Build 133 that showed MAF ranging from 0.15 to 0.20 (A allele). The present results also differ from those in the database in regard to IARS2 segregation. Greater frequencies of the $\mathrm{C}$ allele and $\mathrm{CC}$ genotypes were found here, whereas the dbSNP reports major allele frequencies for the T allele and CT and TT genotypes. The reference of IARS2 in the dbSNP Build 133 reported an MAF ranging from 0.25 to 0.42 for the $\mathrm{C}$ allele.

Some polymorphisms in the calpain (CAPN4753, CAPN4751, CAPN530, CAPN316) and calpastatin (WSUCAST, AF_159246.1:g.2959A $>$ G) genes have been evaluated for their associations with meat tenderness in Nellore cattle (Curi et al., 2009, 2010; Pinto et al., 2010). UoGCAST and CAPN4751 seemed to be the most promising markers for meat tenderness in this breed, but their effects on other productive traits, such as feed intake and feed efficiency, have not yet been established. In the current study, the variability for CAPN4751 and UoGCAST in Nellore cattle, previously reported in other studies (Pinto et al., 2010, 2011), was confirmed, showing that the allelic and genotypic frequencies seem consistent across Nellore populations. Similarly, the cited authors obtained low frequencies for the CC type of CAPN4751 (3.2\%) and well-distributed frequencies across the three genotypes of UoGCAST in agreement with studies in Brahman cattle (White et al., 2005; Casas et al., 2006). The good segregation of these markers in the present study allowed the estimation of allele substitution effects.

The MAFs for GHR-1 and GHR-2 reported by Sherman et al. (2008) in a population composed of Angus, Charolais, and hybrid cattle are greater than those observed in the present study. These authors reported MAF values of 40 and $23 \%$ for the A and G alleles of GHR-1 and GHR-2, respectively. Additionally, that study observed the three genotypes for GHR-1, with a moderate frequency of the AA type (17\%). Unlike GHR-1, it seems that the distribution of the GHR-2 genotypes is very similar across Nellore and taurine cattle. Although other polymorphisms in the promoter region of the GHR gene had been examined in Nellore cattle (Curi et al., 2006), the GHR-1 and GHR-2 had not been previously tested.

The C alleles of UoGCAST and CAPN4751 were favorable for growth, feed efficiency, and fat deposition (single marker analyses). Other investigations reported the positive effect of the $\mathrm{C}$ allele for carcass fat, although it was also associated with decreased longissimus muscle area and bone yield (Schenkel et al., 2006), traits that are suggestive of early maturing and less efficient cattle (Nkrumah et al., 2007). This allele was also reported to be favorable for meat tenderness in other studies (White et al., 2005; Curi et al., 2009; Pinto et al., 2010). Nevertheless, the present results on CAPN4751 are not supported by investigations carried out in B. indicus-influenced cattle (Curi et al., 2009), where no differences between CT and TT genotypes were found for the ribeye area, backfat thickness, and intramuscular fat. 
The polymorphisms evaluated in the GHR promoter region in Nellore cattle had suggestive and significant allelic effects on feed efficiency (RFIw) and carcass traits (initial URFT and final UREA), which agree with the GH effects on tissue growth. Administration of growth hormone acts on nutrient partitioning between muscle and adipose tissue, increasing body protein accretion rates, decreasing lipid accretion, and improving feed efficiency (Etherton and Bauman, 1998), but these effects are dependent on the hormone interaction with GHRs in target tissues (Kopchick and Andry, 2000). Early studies have suggested associations of polymorphisms in the promoter region of the GHR gene with weight gain and carcass weight in Zebu-influenced cattle (Curi et al., 2006), while others have noted associations with body fat deposition (Garrett et al., 2008) and serum insulin-like growth factor I concentration (Ge et al., 2003) in Angus.

In the current study, the G allele of GHR-1 was related to lower initial rump fat thickness and greater ribeye area. This is in agreement with Sherman et al. (2008), who reported that the $\mathrm{G}$ allele was unfavorable for carcass marbling, although no associations were found with backfat thickness and ribeye area in that study. In the same investigation, the G allele of GHR-2 was unfavorable for feed efficiency, which is somehow corroborated by the current study as we observed a trend $(\mathrm{P}<0.10)$ for increasing RFIw.

Allelic substitution effects for PSMD13, IARS2, UBE2I-1, and R3HDM1-4 have not been reported before. The SNP did not have allelic substitution effects on any traits evaluated and may not be useful in the selection for productive traits in Nellore cattle. The results with respect to PSMD13, IARS2, and UBE2I-1 do not agree with their function, as protein turnover corresponds to 30 to $40 \%$ of all energy expended by cattle (Lobley et al., 1980) and notably affects protein accretion rates and energy requirements for maintenance (Morgan et al., 1993; Oddy et al., 1998; Castro Bulle et al., 2007). Polymorphisms in the R3HDM1 have been associated with human cholesterol (Ma et al., 2010), human disease (Muiños-Gimenos et al., 2010), and RFI in beef cattle (Barendse et al., 2007), and gene function has been inferred as being an endopeptidase/endoproteinase inhibitor (Barendse et al., 2007). However, little further information on this gene is available and estimations of allelic substitution effect have not been previously reported.

The use of DNA information through marker panels can significantly increase selection responses (Van Eenennaam et al., 2011). However, it is important to assess individual effects of each marker when evaluated separately or in a set of several SNP. Thus, in the present study, pooled analyses of allelic substitution effects were also performed, whereby all eight segregating SNP were evaluated either in a single whole mixed model (Table 5) or using a stepwise linear regression procedure (Table 6).

Overall, the significance of allelic substitution effects when using a multiple-marker model changed slightly from values observed in the single-marker analyses; some effects no longer showed suggestive significance, whereas others did. There was a general trend towards an increase in the significance of allelic substitution effects in most traits by using a multiplemarker model approach. This might have occurred because the number of parameters being estimated increased considerably, whereas the population size remained the same.

In the stepwise regression procedure, drastic changes in estimates of allelic substitution effects for all traits evaluated were observed. Allelic substitution effects were even observed on traits that had not been affected by markers when using the single-marker model, such as MBW, DMI, and FCR, suggesting that a multi-marker approach may reveal new information. All allelic substitution effects observed in the single-marker analysis were not highlighted us- 
ing the stepwise regression, except for the effects of GHR-2 on RFIw and CAPN4751 on final URFT, although their magnitude markedly decreased from the former to the latter approach.

The MBV were computed by summing the relative contribution of all SNPs and those whose estimates were significant at $P$ values lower than $0.80,0.60,0.40,0.20$, and 0.10 . The same procedure was adopted to calculate MBV from stepwise models. Correlation magnitudes were altered depending on the adopted significance level of markers that contributed to the estimation of the MBV because of the change in the number of SNP in the model across the different levels of significance. However, these changes can be considered small in most traits. The low coefficients of correlation between MBV and phenotypes mean that the set of SNP evaluated explained a small percentage of additive genetic variance of feed intake, feed efficiency, growth, and carcass traits in Nellore cattle.

The markers' effects greatly changed from one statistical procedure to the other. Only 4 of the 15 traits evaluated were related to less than two markers, suggesting that markers can be interacting with each other in epistatic effects, which could partially explain the results. The large estimation errors may also explain this change. On the other hand, we could notice that the magnitude of allelic substitution effects was, in some cases, greater than that reported elsewhere (e.g., Sherman et al., 2008; Ferraz et al., 2009), suggesting the need for other adjustments in the model.

The differences between methods were remarkable when we look at the correlations between the estimated molecular breeding values and the adjusted phenotypes (Table 7). The allelic substitution effects estimated using the stepwise procedure allowed us to compute the individual molecular breeding value for each trait, according to the number of copies of favorable allele for each animal.

A study with taurine cattle (Sherman et al., 2008) reported additive effects of GHR-1 on FCR and RFI, as well as of GHR-2 on BWG, DMI and final BW. In the same study, dominant effects were observed for GHR-1 on PEG and final BW and for GHR-2 on BWG, FCR, DMI, and final BW. These results partially agree with our findings regarding the associations of polymorphisms in the GHR gene with growth traits. It should be borne in mind that dominant effects prevailed for most traits. This could partially explain the low correlations found for estimated MBVs with adjusted phenotypes as well as why some marker effects were not observed in the allelic substitution effect analysis.

The current study reports the association analyses of growth, feed intake, and feed efficiency traits with SNPs that had been either evaluated for effects on only meat quality traits (UoGCAST and CAPN4751) or not fully described for associations with growth and carcass traits (IARS2, UBE2I-1, R3HDM1-4). Original additive and dominant effects were presented on economically relevant traits, providing new knowledge of marker-assisted selection for traits such as feed efficiency. In addition, the potential use of SNPs in the GHR gene in marker-assisted selection for growth in beef cattle was confirmed in the Nellore breed. An interesting result was that the SNP set provided useful information for selecting cattle for RFI, since significant allelic substitution effects were observed and the correlation of MBV and adjusted phenotypes were moderate. Residual feed intake requires long feeding periods to be calculated, which may not be cost-effective. Therefore, adequate panels of markers could increase the accuracy of expected progeny differences and increase the efficiency of selection for feed efficiency.

In Nellore cattle, SNPs associated with residual feed intake in B. p. taurus cattle 
did not show adequate segregation. However, polymorphisms located in or nearby genes of calpain, calpastatin, and GHR, or genes regulating the ubiquitin-proteasome system and the translation step of protein synthesis may be associated with growth, feed efficiency, and carcass traits in additive and dominant effects. Molecular breeding values computed through allelic substitution effects in single- and multiple-marker models were poorly correlated to phenotypes, except for residual feed intake. However, stepwise linear regression analyses may contribute to calculate MBV that are more correlated to phenotypes.

\section{ACKNOWLEDGMENTS}

Research partially supported by Fundação de Amparo à Pesquisa do Estado de São Paulo (FAPESP, \#2007/0445-6, \#2008/10098-0, and \#2008/11363-9).

\section{REFERENCES}

Antoniou E and Gallagher D (2002). Chromosomal assignment of the bovine ubiquitin-conjugating enzyme E2I (UBE2I) gene to BTA6q34 defines a new fragment of conserved synteny with human chromosome 16. Anim. Genet. 33: 388389.

Artero-Castro A, Castellvi J, Garcia A, Hernandez J, et al. (2011). Expression of the ribosomal proteins Rplp0, Rplp1, and Rplp2 in gynecologic tumors. Hum. Pathol. 42: 194-203.

Barendse W, Reverter A, Bunch RJ, Harrison BE, et al. (2007). A validated whole-genome association study of efficient food conversion in cattle. Genetics 176: 1893-1905.

Casas E, White SN, Wheeler TL, Shackelford SD, et al. (2006). Effects of calpastatin and micro-calpain markers in beef cattle on tenderness traits. J. Anim. Sci. 84: 520-525.

Castro Bulle FC, Paulino PV, Sanches AC and Sainz RD (2007). Growth, carcass quality, and protein and energy metabolism in beef cattle with different growth potentials and residual feed intakes. J. Anim. Sci. 85: 928-936.

Ciechanover A (1998). The ubiquitin-proteasome pathway: on protein death and cell life. EMBO J. 17: 7151-7160.

Curi RA, Palmieri DA, Suguisawa L, Ferraz ALJ, et al. (2006). Effects of GHR gene polymorphisms on growth and carcass traits in Zebu and crossbred beef cattle. Livest. Prod. Sci. 101: 94-100.

Curi RA, Chardulo LA, Mason MC, Arrigoni MD, et al. (2009). Effect of single nucleotide polymorphisms of CAPN1 and CAST genes on meat traits in Nellore beef cattle (Bos indicus) and in their crosses with Bos taurus. Anim. Genet. 40: 456-462.

Curi RA, Chardulo LA, Giusti J, Silveira AC, et al. (2010). Assessment of GH1, CAPN1 and CAST polymorphisms as markers of carcass and meat traits in Bos indicus and Bos taurus-Bos indicus cross beef cattle. Meat. Sci. 86: 915-920.

Eriani G, Delarue M, Poch O, Gangloff J, et al. (1990). Partition of tRNA synthetases into two classes based on mutually exclusive sets of sequence motifs. Nature 347: 203-206.

Etherton TD and Bauman DE (1998). Biology of somatotropin in growth and lactation of domestic animals. Physiol. Rev. 78: 745-761.

Falconer DS and Mackay TFC (1996). Introduction to Quantitative Genetics. 4th edn. Longman Scientific and Technical, New York

Ferraz JB, Pinto LF, Meirelles FV, Eler JP, et al. (2009). Association of single nucleotide polymorphisms with carcass traits in Nellore cattle. Genet. Mol. Res. 8: 1360-1366.

Garrett AJ, Rincon G, Medrano JF, Elzo MA, et al. (2008). Promoter region of the bovine growth hormone receptor gene: single nucleotide polymorphism discovery in cattle and association with performance in Brangus bulls. J. Anim. Sci. 86: 3315-3323.

Ge W, Davis ME, Hines HC and Irvin KM (1999). Two-allelic DGGE polymorphism detected in the promoter region of the bovine GHR gene. Anim. Genet. 30: 71.

Ge W, Davis ME, Hines HC, Irvin KM, et al. (2003). Association of single nucleotide polymorphisms in the growth hormone and growth hormone receptor genes with blood serum insulin-like growth factor I concentration and growth traits in Angus cattle. J. Anim. Sci. 81: 641-648.

Goll DE, Neti G, Mares SW and Thompson VF (2008). Myofibrillar protein turnover: the proteasome and the calpains. $J$. Anim. Sci. 86: E19-E35. 
Hershko A and Ciechanover A (1998). The ubiquitin system. Annu. Rev. Biochem. 67: 425-479.

Ihara M, Stein P and Schultz RM (2008). UBE2I (UBC9), a SUMO-conjugating enzyme, localizes to nuclear speckles and stimulates transcription in mouse oocytes. Biol. Reprod. 79: 906-913.

Johnson ES (2004). Protein modification by SUMO. Annu. Rev. Biochem. 73: 355-382.

Kopchick JJ and Andry JM (2000). Growth hormone (GH), GH receptor, and signal transduction. Mol. Genet. Metab. 71: 293-314.

Lobley GE, Milne V, Lovie JM, Reeds PJ, et al. (1980). Whole body and tissue protein synthesis in cattle. Br. J. Nutr. 43: 491-502.

Lorick KL, Jensen JP, Fang S, Ong AM, et al. (1999). RING fingers mediate ubiquitin-conjugating enzyme (E2)-dependent ubiquitination. Proc. Natl. Acad. Sci. U. S. A. 96: 11364-11369.

Ma L, Yang J, Runesha HB, Tanaka T, et al. (2010). Genome-wide association analysis of total cholesterol and highdensity lipoprotein cholesterol levels using the Framingham heart study data. BMC Med. Genet. 11: 55.

Maj A and Zwierzchowski L (2006). Molecular evolution of coding and non-coding sequences of the growth hormone receptor (GHR) gene in the family Bovidae. Folia Biol. 54: 31-36.

Morgan JB, Wheeler TL, Koohmaraie M, Crouse JD, et al. (1993). Effect of castration on myofibrillar protein turnover, endogenous proteinase activities, and muscle growth in bovine skeletal muscle. J. Anim. Sci. 71: 408-414.

Muiños-Gimeno M, Montfort M, Bayes M, Estivill X, et al. (2010). Design and evaluation of a panel of single-nucleotide polymorphisms in microRNA genomic regions for association studies in human disease. Eur. J. Hum. Genet. 18: 218-226.

Niwa J, Ishigaki S, Doyu M, Suzuki T, et al. (2001). A novel centrosomal ring-finger protein, dorfin, mediates ubiquitin ligase activity. Biochem. Biophys. Res. Commun. 281: 706-713.

Nkrumah JD, Basarab JA, Wang Z, Li C, et al. (2007). Genetic and phenotypic relationships of feed intake and measures of efficiency with growth and carcass merit of beef cattle. J. Anim. Sci. 85: 2711-2720.

Oddy VH, Herd RM, McDonagh MB, Woodgate R, et al. (1998). Effect of divergent selection for yearling growth rate on protein metabolism in hind-limb muscle and whole body of Angus cattle. Livest. Prod. Sci. 56: 225-231.

Olerup O and Zetterquist H (1992). HLA-DR typing by PCR amplification with sequence-specific primers (PCR-SSCP) in 2 hours: An alternative to serological DR typing in clinical practice including donor-recipient matching in cadaveric transplantation. Tissue Antigens 39: 225-235.

Pinto LF, Ferraz JB, Meirelles FV, Eler JP, et al. (2010). Association of SNPs on CAPN1 and CAST genes with tenderness in Nellore cattle. Genet. Mol. Res. 9: 1431-1442.

Pinto LF, Ferraz JB, Pedrosa VB, Eler JP, et al. (2011). Single nucleotide polymorphisms in CAPN and leptin genes associated with meat color and tenderness in Nellore cattle. Genet. Mol. Res. 10: 2057-2064.

SAS (2004). SAS/STAT User's Guide. Version 9.1. SAS Institute, North Carolina.

Schenkel FS, Miller SP, Jiang Z, Mandell IB, et al. (2006). Association of a single nucleotide polymorphism in the calpastatin gene with carcass and meat quality traits of beef cattle. J. Anim. Sci. 84: 291-299.

Sherman EL, Nkrumah JD, Murdoch BM, Li C, et al. (2008). Polymorphisms and haplotypes in the bovine neuropeptide $\mathrm{Y}$, growth hormone receptor, ghrelin, insulin-like growth factor 2, and uncoupling proteins 2 and 3 genes and their associations with measures of growth, performance, feed efficiency, and carcass merit in beef cattle. J. Anim. Sci. 86: $1-16$

Valadares Filho SC, Paulino PVR and Magalhães KA (2006). Exigências Nutricionais de Zebuínos e Tabelas de Composição de Alimentos BR-Corte. 21 ed. UFV, Viçosa.

Van Eenennaam AL, van der Werf JH and Goddard ME (2011). The value of using DNA markers for beef bull selection in the seedstock sector. J. Anim. Sci. 89: 307-320.

Vogiatzis I, Simoes DC, Stratakos G, Kourepini E, et al. (2010). Effect of pulmonary rehabilitation on muscle remodelling in cachectic patients with COPD. Eur. Respir. J. 36: 301-310.

White SN, Casas E, Wheeler TL, Shackelford SD, et al. (2005). A new single nucleotide polymorphism in CAPN1 extends the current tenderness marker test to include cattle of Bos indicus, Bos taurus, and crossbred descent. J. Anim. Sci. 83: 2001-2008

Zhao J (2007). Sumoylation regulates diverse biological processes. Cell Mol. Life Sci. 64: 3017-3033. 